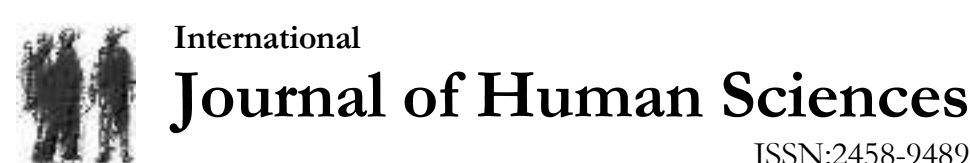

Volume: 18 Issue: 4 Year: 2021

\section{Computer-Aided Language Learning (CALL) used in the example of Sakarya University}

\author{
Ulvican Yazar ${ }^{1}$ \\ Nail Abalı ${ }^{2}$
}

\begin{abstract}
Considering the ubiquity of computers and the Internet in this ever changing technological era, it is definitely normal that they would affect the language learning process. As an institution, Sakarya University is supposed to keep pace with the technology in every field. Thereupon, CALL started being used at English Language Preparatory Class of Sakarya University.

Computer-Aided Language Learning (CALL) is the fulfilment of software and web-based programs to ease the learning of English. CALL can be a good supplementary tool it cannot only be used like traditional face-to-face instruction.

An increased use of computers and the advent of the Internet in every field of modern lifestyle make computer-aided language learning irreplaceable in all aspects. Being new to those who were fond of the high technology and who were fed up with using books, CALL grabbed the students' attention, which made the study easier. In the system, Computers were tools that students mainly utilized. Every student had a computer reserved for himself/herself. It was an amazing experience for those using books.

In this study it is aimed to evaluate CALL implemented at English Language Preparatory Class of Sakarya University and assess the students' performances. The data analysis method was used. The data were able to be managed and analyzed properly and effectively after the conclusions of the research. The success results of the Sakarya University preparatory class students were evaluated. The data utilized in the study are restricted to the period of three academic years. According to results CALL has been successfully applied in years when the software used was upto-date. In line with the results, CALL is a useful tool that helps teachers to ease the language learning process.
\end{abstract}

Keywords: CALL; computer-aided language learners; computer-aided language learning; behavoristic CALL; commucative CALL; integrative CALL.

\footnotetext{
1 Ph.D., Sakarya University, Foreign Languages Department, uyazar@sakarya.edu.tr

(iD) Orcid ID: 0000-0002-5991-0637

2 Lec., Sakarya University, Foreign Languages Department, nabali@sakarya.edu.tr

(iD) Orcid ID: 0000-0001-6700-2527 
Yazar, U., \& Abalı, N. (2021). Computer-Aided Language Learning (CALL) used in the example of Sakarya University. Journal of Human Sciences, 18(4), 529-535. doi:10.14687/jhs.v18i4.6219

\section{Introduction}

In parallel with the rapid progress of technology, governments are trying to make technology a part of education activities in order to increase educational efficiency. However, in order for technology to make positive contributions to the education process and teaching process, both technology, pedagogy and subject knowledge should contribute in the way they should.

It is inevitable to use the computer, which is a part of our lives and one of the most important technological tools used today in the educational environment. Supporting the traditional course materials used in foreign language education with the possibilities of computer technology is important in terms of increasing efficiency in language learning.

Language learning is a difficult but fun process. In this process, it was thought that computer-assisted programs would be more efficient in order to make learning more lively and enjoyable, and computer-assisted education system was preferred in the language teaching process. CALL is not a language teaching method but a helpful tool for language learning.

\section{What is CALL?}

There are many definition made for CALL. Basically the word "CALL" is an acronym for Computer-Aided Language Learning. CALL is broadly used to intend to the both area of second language learning and technology and teaching in spite of updating for the term can be proposed widely (Chapelle, 2001, 3).

Computer Aided Language Learning (CALL) can be explained as examining the applications of computers in language learning and teaching. (Levy, 1997, 1). One definition encompassing the changing nature of CALL is any process by which a learner of any languages uses a computer and eventually develops her or his language. (Beatty, 2003, 7).

The future of computer-aided language learning (CALL) related to lot of factors, such as research in applied linguistics, differentiations in languages and language learning, and also sociological differentiations in schools and education system. Among them technological changes may be the most important factor that influence the future of CALL. (Warschauer, 2004, 15-25)

\section{History of CALL}

There were some approaches to teach specific languages in the 1950s and 1960s on host computers but the first scale project was applied with the PLATO system which was improved at the University of Illinois. (Beatty, 2003, 7)

Computers have been an important tool for language teaching for decades. This history can be roundly divided into three main periods: behavioristic CALL, communicative CALL, and integrative CALL. Each period is specific with a definite level of technology and also definite pedagogical approach.

There are three stages in the development of CALL according to the pedagogical perspective. These are as follows

\section{Behavioristic CALL}

The first stage is basically dependent on some paradigms such as Grammar-Translation and Audio-lingual approaches. In Behavioristic CALL, computers are commonly used to do drills and practice. The main priority is language accuracy. It is defined as a formal structural system. In the paradigm, the computer is assumed as a mechanical teacher that never gets tired, gets angry or judgmental and it helps students to study at their own individual pace. PLATO which is regarded as the most familiar tutorial system, runs on its own, a host computer and terminals and featured comprehensive exercises, grammar explanations and translation tests at various intervals are part of the special equipment. Ahmad, Corbett, Rogers, \& Sussex, 1985). In 1960, PLATO (Programmed Logic for Automated Teaching Operations) was improved and firstly paid attention to vocabulary and grammar drill exercises. Warschauer and Healey $(1998,57)$ 
Yazar, U., \& Abalı, N. (2021). Computer-Aided Language Learning (CALL) used in the example of Sakarya University. Journal of Human Sciences, 18(4), 529-535. doi:10.14687/jhs.v18i4.6219

Language laboratories, which are important aspects of the auditory-linguistic language teaching method, have an important role in this paradigm, providing increased opportunities for students to hear and repeat the language.

\section{Communicative CALL}

The stage stems from a mentally constructed system through interaction. In other words it is cognitive. Communicative Language teaching is a paradigm used in Communicative CALL.

The principal use of computers is for doing Communicative Exercises.

Unlike Structural CALL, fluency plays an important role in Communicative CALL. Advocates of communicative CALL emphasize that computer-based activities should be about using the forms themselves instead of the forms only, and teaching grammar should be preferred to teach implicitly not explicitly and also allow and encourage students to generate original expressions rather than just manipulate pre-prepared language, and target language should be used predominantly or even specifically.(Jones \& Fortescue, 1987; Phillips, 1987; Underwood, 1984).

\section{Integrative CALL}

In the stage, sociocognitive approach improved in social coaction by discourse communities is crucial. A Content-based paradigm has priority. The main use of computers is to do real-life tasks known as authentic discourse. The approach integrates some skills into the language learning process, such as; more comprehensively speaking, listening, reading, and writing and technology. The stage is divided into two forms such as Multimedia CALL based on CD-ROMs and Webfounded CALL on the Internet.

In Multimedia CALL, a unique learning environment is created by using distinct media environments. Language skills are smoothly joint via multimedia.

In the web-based CALL, students can search millions of files worldwide to access real materials and find and retrieve files precisely adapted to their personal interests in minutes. Learners can use the World Wide Web to publish their studies or materials consist of multimedia to share with classmates or with everyone else.

In the late 1990s, the development of CD-ROMs, rising entrance to the Internet, and the emergence of multimedia computers facilitated language learning through text, audio, graphics, and video, leading to the further development of the integrative CALL. Students begin to control what, when and how they learn. Broad access by students to authentic materials for instance, newspapers, magazines, videos, TV and radio broadcasts has considerably increased the possible language learning chances available, both by herself or himself and in the classroom. According to Warschauer and Healey $(1998,57)$, global knowledge-based economies must have a large amount of knowledge and communication across languages and cultures.

\section{Information about the Program}

The programme used by Sakarya University was for blended language learning underpinned by modern pedagogical approaches from the educational world. It was aimed to integrate not only traditional learning components, such as online computer activities, but also communicative and enrichment activities, and a variety of assessment tools.

It encompassed a range of courses designed to produce an enjoyable, motivating, and effective language-learning experience. It was correlated to the standards of the Common European Framework, and taught English to learners from beginner to low-advanced levels. Its computer-based components employed state-of-the-art technology that allowed a choice of multiple platforms to enable self-study for segments such as schools, training centers, governmental agencies, and institutions, and provided English tuition to all levels of learners, from one centralized platform. 
Yazar, U., \& Abalı, N. (2021). Computer-Aided Language Learning (CALL) used in the example of Sakarya University. Journal of Human Sciences, 18(4), 529-535. doi:10.14687/jhs.v18i4.6219

It provided a successful model of blended learning. Quartet's computer-based course materials allowed learners to reap the pedagogical benefits that the richness of multimedia and the individualization of self-paced learning afford. Internet-based language learning combined all of the benefits of traditional computer-based language learning programs with the communication tools and information resources available on the Internet. Students could learn from anywhere in the world at any time, practicing their language skills in real-life situations.

The system allowed students and teachers to become parts of a virtual community of English language learners and instructors. In this virtual community, teachers obtained lesson plans and new materials to use in their classrooms. They also got tips and hints to improve their teaching by sharing their teaching experiences with other teachers. For students, the virtual community offered the opportunity to use the language skills that they acquired in the classroom in real life situations.

Pedagogical and technological training and support allowed both students and teachers to attain the full benefits of the system. It provided a platform framework allowing the integration of course and learning management capabilities through its SCORM-compliant system. It was able to deliver as a complete system or as independent educational content, adaptable to any SCORMcompliant Learning Management System.

The system was designed by pedagogical experts for learners. The principles below were the pedagogical foundations upon which the system was built. They allowed learners to acquire the language skills and strategies they needed to develop fluency and coped in a competitive world where English is essential.

In the programme, language was learned best by employing tools and language-learning components to do what they did best, within the comprehensive system that it provided. Learning language necessitated mastery of many skills which might be presented and/or reinforced through computer-based materials, in the classroom, or at home; individually, in pairs, or in groups. Therefore, it offered the tools necessary to both learners and teachers that facilitated efficient language learning.

The system reflected sound pedagogical underpinnings of computer-based language learning. The materials stimulated and empowered learners by engaging them in a variety of media in a single program, including video, audio, text, graphics, and animation.

Computer-based learning presumed the development of a learning environment where multisensory presentation (visual, auditory, and kinaesthetic) was provided, and language learning skills were developed on this foundation. Feedback was immediate, and learning became selfreinforcing.

The system allowed learners choice. In the course of using the system, learners could rely on both their knowledge of English, and on their individual preferences in order to make appropriate and informed choices regarding the learning process.

It was believed that English was used in all parts of the world, and the system reflected awareness of the fact that learners came from different cultures and backgrounds. It celebrated the diversity of students by incorporating the voices and characters of people from many different linguistic and cultural backgrounds in carefully selected, authentic situations.

The themes used in the system were re-entered and built upon from level to level. The syllabus was developmental, with chapters of each level expanding on the themes of the previous levels.

People were believed to learn by doing. Therefore, all activities in the programme demanded interaction by the learner. Visual and auditory interaction with the text, as well as interaction through activities, engaged the learner and assisted him/her in internalizing the material being presented.

It made the learner a partner in the assessment process by providing feedback on activities at the learner's request. This formative feedback was enhanced by encouraging learners to utilize 
links to reference tools which assisted them in completing or correcting activities. Summative feedback was provided through final checkpoints for each level.

The programme used English exclusively as the language of content. Support language elements were provided in the learner's native language in order to facilitate, use of the software. All reference tools for instance, listening, reading and language tips included rules and generalizations in the student's native language and examples in English.Instructions to activities could appear at the learner's prompt in both English or in the native language.

\section{Data Analysis of CALL Implemented at Sakarya University}

CALL was used at Sakarya University. The programme had two terms, one of which had 14 weeks. The data related to three years from 2011 to 2014 were assessed below. These data were taken from Sakarya University Foreign Language Department. In the programme lasting 28 weeks, the average score of success was 70 out of 100 . The number of students participating in the programme per year was approximately 450.

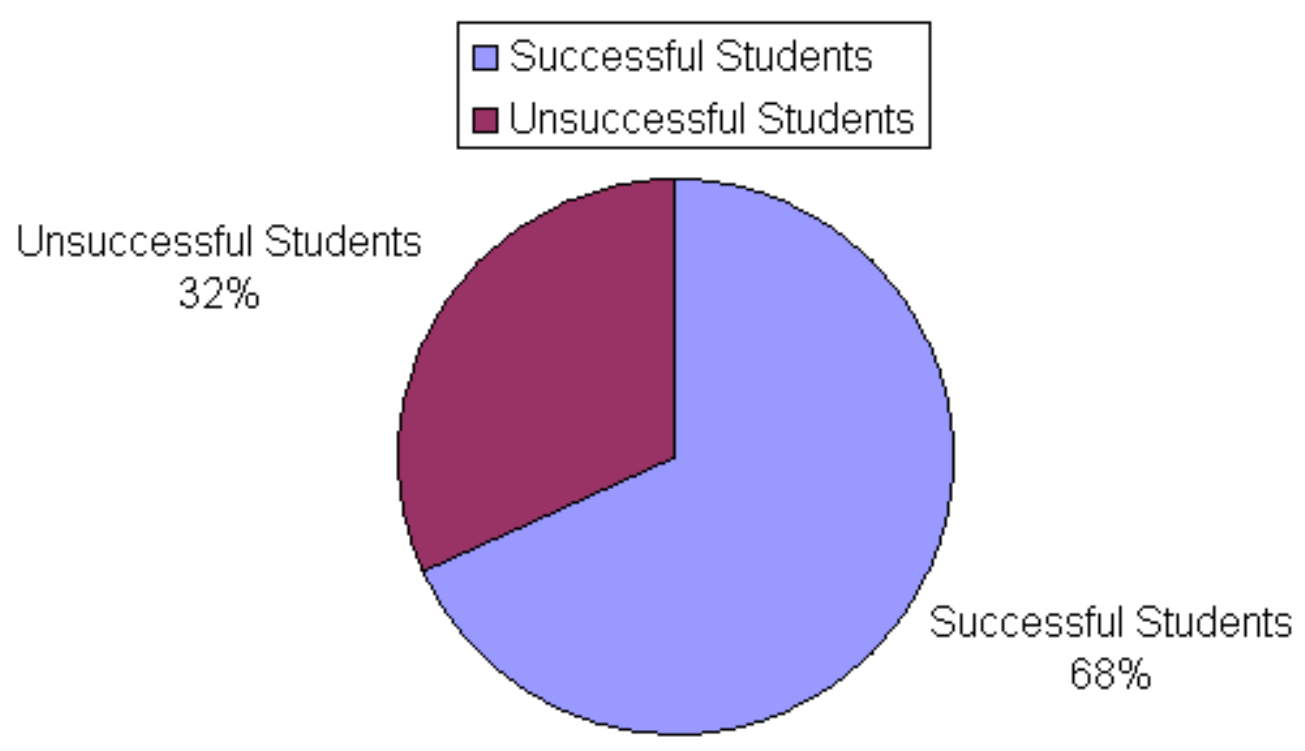

Figure 1: Students' achievements in the 2011-2012 academic year.

As shown in the pie chart above, $68 \%$ of students succeeded while $32 \%$ of students failed in accordance with the data of the academic year 2011 - 2012 


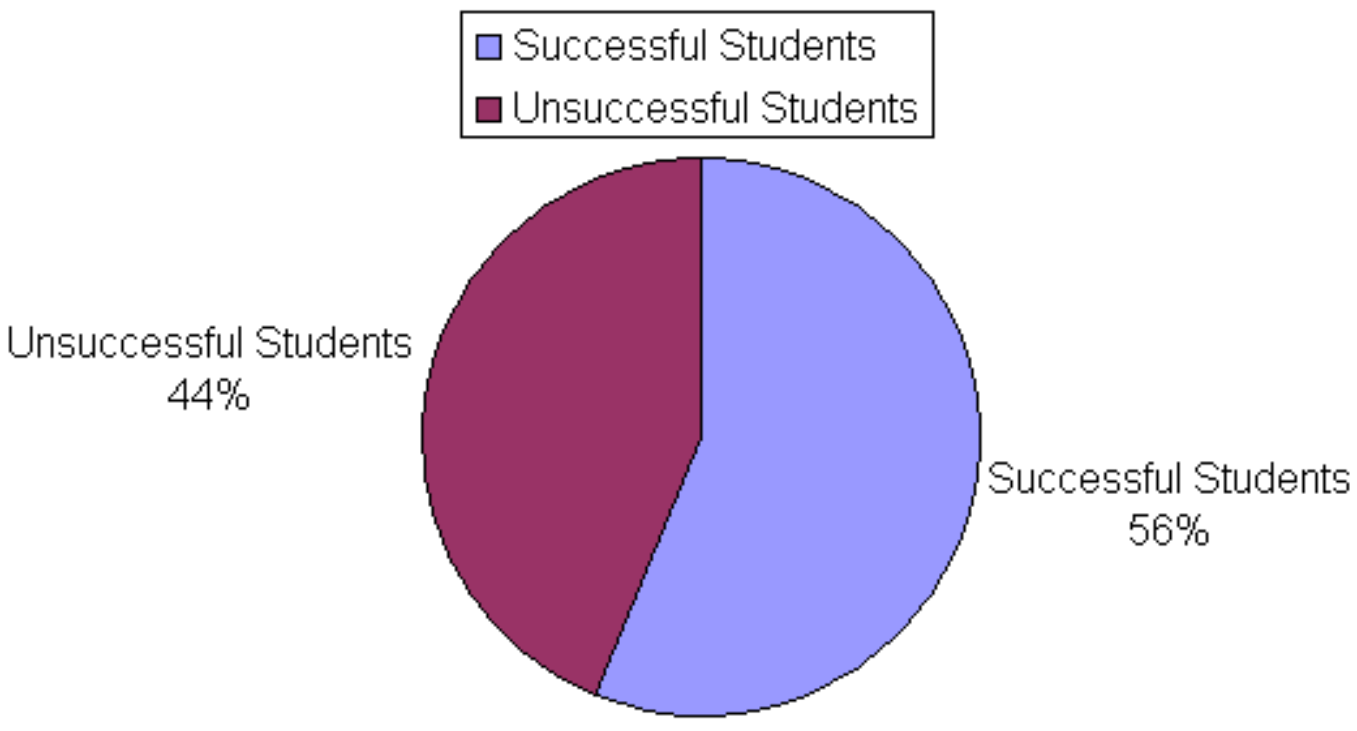

Figure 2: Students' achievements in the 2012-2013 academic year.

As shown in the pie chart above, $56 \%$ of students succeeded whereas $44 \%$ of students failed in accordance with the data of the academic year 2012 - 2013
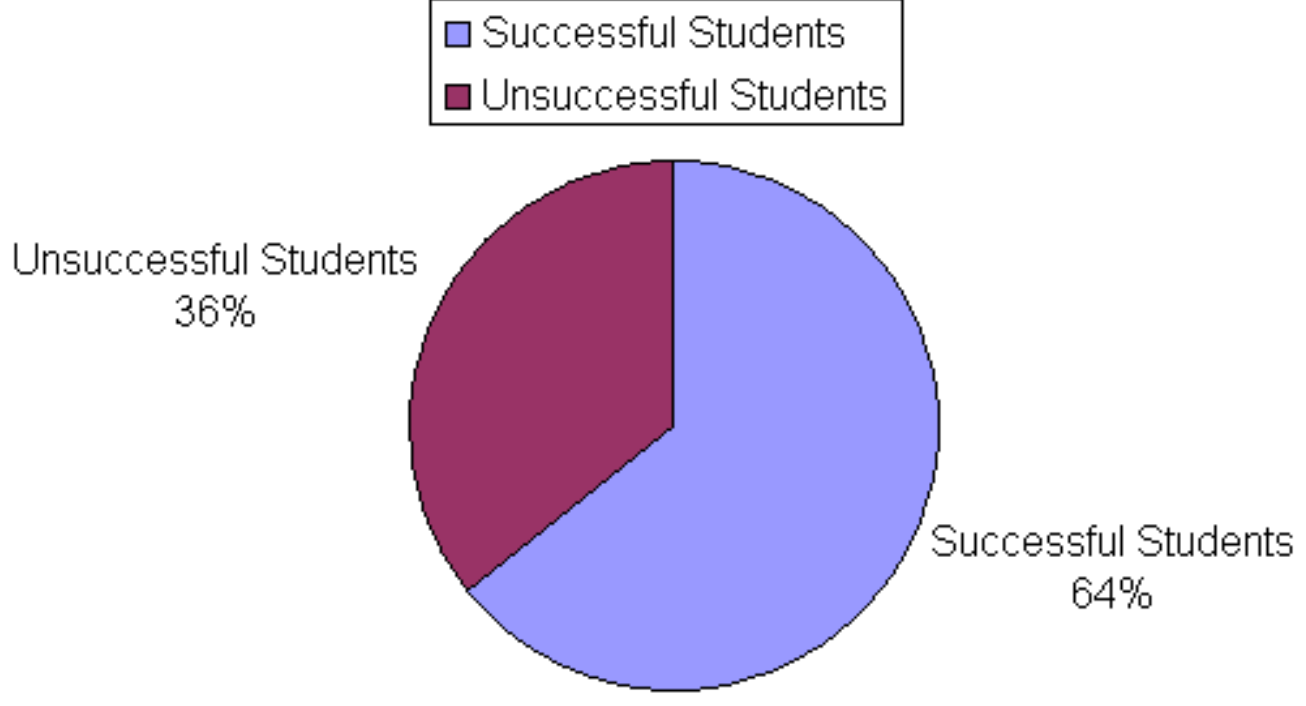

Figure 3: Students' achievements in the 2013-2014 academic year.

As shown in the pie chart above, $64 \%$ of students succeeded whereas $36 \%$ of students failed in accordance with the data of the academic year 2013 - 2014

\section{Conclusion and Recommendation}

CALL is open to new changes. It provides teachers a lot of opportunities to show their students the real facet of the target language with joy. The data aforementioned suggested that CALL had been successfully used at Sakarya University. The program integrated all skills. Thus, students adapted to CALL easily and thanks to the adaptation, they managed to reach success.

Call implemented successfully at Sakarya University when the software used was up to date. Yet the software used in Call should have been upgraded, and also it should have been overhauled considering students' needs, goals, materials and technology available under the frame of 
pedagogical and educational perspectives and experiences. For instance, new authentic reading material, movies, some interesting video clips including beneficial materials for learning and songs should have been embedded in the software, which motivated students so much that they would probably desire to study and attend classes.

Since such changes and updates had not been made periodically to the system, this system lost its popularity and was left. That is to say, it was no longer used in Sakarya University. An increased use of computers in every field of modern lifestyle made computer-assisted language learning irreplaceable in all aspects. As an institution, Sakarya University was supposed to keep pace with the ever-changing technology. So did it.

\section{References}

Ahmad K., Corbett G., Rogers M., \& Sussex R. (1985) Computers, language learning and language teaching, Cambridge: Cambridge University Press.

Beatty, K. (2003) Teaching and Researching Computer Assisted Language Learning, New York: Longman, 7

Chapelle, C. A. (2001). Computer applications in second language acquisition. New York: Cambridge, 3

Jones, C. \& S. Fortescue. (1987) Using Computers in the Language Classroom. London: Longman

Kern, R., \& Warschauer, M. (2000). Theory and practice of network-based language teaching. In M. Warschauer \& R. Kern (Eds.), Network-based language teaching: Concepts and practice New York: Cambridge University Press, 1-19

Levy, M. (1997) CALL: Context and conceptualization. Oxford: Oxford University Press, 1

Phillips, M.(1987). Communicative language teaching and the microcomputer. London: The British Council

Warschauer, M. and Healey, D. (1998). Computers and language learning: an overview. Language Teach, 57-71

Warschauer, M. (2004). Technological change and the future of CALL. In S. Fotos \& C. Brown (Eds.),New Perspectives on CALL for Second and Foreign Language Classrooms, 15-25. Mahwah, NJ: Lawrence Erlbaum Associates.

Underwood, J. (1984). Linguistics, computers, and the language teacher. Rowley, MA: Newbury House. 